\title{
An empirical study of international oil price and RMB exchange rate return spillover effect
}

\author{
Fan Xiao*, Zhiyu An \\ School of Economic \& Management Nanjing University of Science and Technology Nanjing, China \\ *Corresponding author: 1041202133@qq.com
}

\begin{abstract}
Using the spillover index method proposed by Diebold and Yilmaz(2012), we examine the return spillover effect between oil market and three major markets of the RMB exchange rate (CNY, NDF, CNH market ). We find that there exists a return spillover effect between oil market and three RMB exchange rate markets, and oil price is the absolute contributor of information overflow. Furthermore, we explore the impact of "811" exchange rate reform on the relationship between oil and exchange rate market. We find after the reform, the spillover from oil market to exchange rate market decreases while the spillover in the opposite direction increases. We also employ the rolling window technique and find return spillovers between the oil and exchange rate markets are timevarying.
\end{abstract}

Keywords: Oil Price; Exchange Rate; Onshore Market; Offshore Market; Spillover Effect

\section{Introduction}

\subsection{Research background}

Oil is an important energy source and strategic material for a country. Since 2017, China has overtaken the United States to become the world's largest oil importer. China's external dependence on oil has risen to $69.8 \%$ in 2018 . Due to the high dependence of oil on the outside, changes in oil prices are more likely to be transmitted to the domestic economy. With the development of crude oil futures market, crude oil has gone beyond the properties of energy, with certain financial attributes. Fluctuations in crude oil prices are affected not only by supply and demand, but also by other financial market interactions, such as exchange rate markets. China's exchange rate market has also experienced rapid development in recent years. The Hong Kong Offshore RMB Market (CNH Market) was formally established in 2010, with the existing onshore interbank foreign exchange market (CNY market) and the Hong Kong offshore non-deliverable forward market (NDFmarket), the three major markets of RMB exchange rate have been formally formed. On August 11, 2015, the central bank announced the start of a new round of RMB exchange rate reform, referred to as "8. 11" exchange rate reform. The exchange rate reform has brought a major impact on the exchange rate market and indirectly affected other financial markets as well as commodity markets. Therefore, although there have been many research articles on the relationship between international oil prices and the RMB exchange rate, it still makes sense to study the subject today.

\subsection{Literature Review}

Liu (2010) used the VAR model to study the conduction of the international oil price shock to the real bilateral exchange rate of RMB/USD, and found that the international oil price shock was the Granger cause of the RMB real exchange rate. Li et al. (2014) used the Generalized VAR model and found that the impact of oil price changes is an important factor in the movement of RMB exchange rate in both short-term and long-term term, but the long-term impact of domestic economic variables such as RMB exchange rate on crude oil prices is very small. Liu (2011) used co-integration test and VEC model and found that there is a long-term co-integration relationship between RMB appreciation expectations and international oil prices, but in the short term there is only a one-way conduction effect of international oil prices on RMB appreciation expectations. Liu et al. (2017) used Wavelet analysis to study the time-frequency characteristics between Brent crude oil futures and the RMB exchange rate, and found that there was a significant negative correlation between the two. 
Jiang et al. (2020) employ the relatively novel quantile-on-quantile and causality-in-quantiles approaches to empirically address the effects of oil price shocks on exchange rates of developed and developing countries and find the evidence of the effects of oil shocks on exchange rates vary across quantiles. Huang et al. (2020) use a hybrid research framework to investigate the co-movement of responses to oil price shocks of four major exchange rate of currencies included in the Special Drawing Rights basket from a time varying aspect and considering the asymmetric effect of the oil price shocks. Malik et al. (2019) use a novel method of isolating the oil price shocks to study how different sources of oil price shocks are connected to exchange rates of major oil-dependent countries, finding that oil price shocks resulting from changes in demand and risk significantly contribute to variation in exchange rates, while supply shocks have virtually no impact.

\subsection{Research significance}

There are more researches on return spillover effect between oil and individual exchange rate market, and less papers between oil and the three RMB exchange rate markets. We think that the three major exchange rate markets have great differences in the participants, pricing mechanism and strict degree of supervision, and only studying the individual market will ignore its heterogeneity. Therefore, we study the return spillover relationship between oil price and three exchange rate markets at the same time. In addition, the above analysis of spillage is mainly based on the VAR, GARCH models, the Granger causal test and pulse response. By reading the literature, we found that the spillover index method proposed by Diebold and Yilmaz (2012) can better reflect the direction and extent of return spillover. So we use this approach to study spillover relationships. This is also a highlight of this article.

\section{Research and design}

\subsection{Sample Selection}

We use the daily future price of WTI, closing price of CNY spot market, the 3-month contract in the NDF market, and CNH spot market. Our sample data cover the period from May 2, 2012 to December 31, 2019. We remove the non-common business days, resulting in a total of 1746 observations. The exchange rate data are collected from Wind database, and WTI are collected from the U.S. Energy Agency (EIA). We take the first order differences of prices as the returns.

$$
R_{i, t}=100 *\left(\ln P_{i, t}-\ln P_{i, t-1}\right.
$$

\subsection{Research method}

Return spillovers are changes in prices or returns in one market that may cause changes in other markets, which generally have a positive or negative effect. For example, the depreciation of the dollar will cause the price of oil to rise.

We use the Spillover Index presented by Diebold and Yilmaz $(2009,2012)$ to examine the scale and direction of the oil and exchange rate market return spillover. Under the framework of the generalized VAR model, the model redefines and measures the direction of spillover effect, eliminating the effect of variable order on the result in the traditional variance decomposition method. Consider the covariance-stationary N-variables VAR (p):

$$
X_{t}=\sum_{i=1}^{p} \Phi_{i} X_{t-i}+\varepsilon_{t}
$$

The moving average process is:

$$
X_{t}=\sum_{i=0}^{\infty} \Phi_{i} A_{i} \varepsilon_{t-i}
$$


Where, the coefficient matrix of $N \times N, A_{i}$ is satisfied with the following Recursive equation:

$$
A_{i}=\Phi_{1} A_{i-1}+\Phi_{2} A_{i-2}+\cdots+\Phi_{p} A_{i-p}
$$

$A_{0}$ Is an $N \times N$ identity matrix, and $A_{i}=0$ for $i<0$. The coefficient in the moving average equation is the decisive factor of system's dynamic transformation, and it is also the main influence factor of variance decomposition. The calculation requirement of traditional variance decomposition requires that the information is orthogonal, whereas in fact the information generally exists in the same period of correlation. The traditional Choleskey decomposition method can achieve orthogonalization, but the result of decomposition depends on the order of variables. Diebold and Yilmaz (2012) use the Generalized VAR Analysis Framework (KPPS) and developed a variance decomposition that is independent of the order of variables. Thus, the results from the DY method are not affected by the order of variables in the VAR system. Since the information shock of each variable is not normalized, the sum of the variance decomposition obtained is not necessarily equal to 1 .

Diebold and Yilmaz (2012) defines "own variance shares" as the fraction of the h-step-ahead error variances in predicting $X i$ due to shocks to $X i$ and "cross variance shares" as the fractions of the hstep-ahead error variances in predicting $X i$ due to shocks to $X j(i \neq j)$.

The KPPS h-step-ahead forecast error variance decomposition is given as follows:

$$
\begin{gathered}
\tilde{\theta}_{i j}^{g}(H)=\frac{\sigma_{j j} \sum_{h=0}^{H-1}\left(e_{i}{ }^{\prime} A_{h} \sum e_{j}\right)^{2}}{\sum_{h=0}^{H-1}\left(e_{i}{ }^{\prime} A_{h} \sum A_{h} e_{j}\right)} \\
(H=1,2, \ldots, K)
\end{gathered}
$$

Where $\sum$ is the variance covariance matrix of the error $\varepsilon$ vector, $\sigma_{j j}$ is the standard deviation of the error term for the $j$ th equation, and $e_{i}$ is the select vector with 1 as the ith element, and 0 otherwise. In order to calculate the spillover index, each variance decomposition matrix is standardized by the row.

$$
\tilde{\theta}_{i j}^{g}(H)=\frac{\theta_{i j}^{g}(H)}{\sum_{j=1}^{N} \theta_{i j}^{g}(H)}
$$

Noting that through the above construction,

$$
\sum_{j=1}^{N} \tilde{\theta}_{i j}^{g}(H)=1, \sum_{i, j=1}^{N} \tilde{\theta}_{i j}^{g}(H)=N
$$

\subsubsection{Total Spillovers}

Based on the KPPS variance decomposition, the total spillover index is constructed as follows:

$$
S^{g}(H)=\frac{\sum_{i, j=1 i \neq j}^{N} \widetilde{\theta}_{i j}^{g}(H)}{\sum_{i, j=1}^{N} \widetilde{\theta}_{i j}^{g}(H)} \times 100
$$

The index measures the contributions from shocks across various markets to the total forecast error variance.

\subsubsection{Directional Spillovers}

In addition to the total spillover index mentioned above, the directional spillovers between variables can be further analyzed. The directional spillover to variable $i$ from all other variables $j$ as: 
Volume 16 (2021)

$$
S_{i \leftarrow}^{g}(H)=\frac{\sum_{j=1 i \neq j}^{N} \widetilde{\theta}_{i j}^{g}(H)}{\sum_{i, j=1}^{N} \widetilde{\theta}_{i j}^{g}(H)} \times 100
$$

We can also calculate the directional spillovers from variable $i$ to all other variable $\mathrm{s} j$ as:

$$
S_{i \rightarrow}^{g}(H)=\frac{\sum_{j=1 i \neq j}^{N} \widetilde{\theta}_{j i}^{g}(H)}{\sum_{i, j=1}^{N} \widetilde{\theta}_{j i}^{g}(H)} \times 100
$$

In fact, the directional spillover effect can be understood as the part of the total spillover effect that comes from a variable-specific shock.

\subsubsection{Net Spillover}

The net spillover is the difference between the two directional spillovers, and the net spillover of the variable $i$ to all other variables is:

$$
S_{i}^{g}(H)=S_{i \rightarrow}^{g}(H)-S_{i \leftarrow}^{g}(H)
$$

If $S_{i}^{g}(H)>0$, the variable $\mathrm{i}$ is the net-contributor of volatility shocks; otherwise, variable $\mathrm{i}$ is a netrecipient.

\section{Empirical analysis}

\subsection{Descriptive Statistical Analysis}
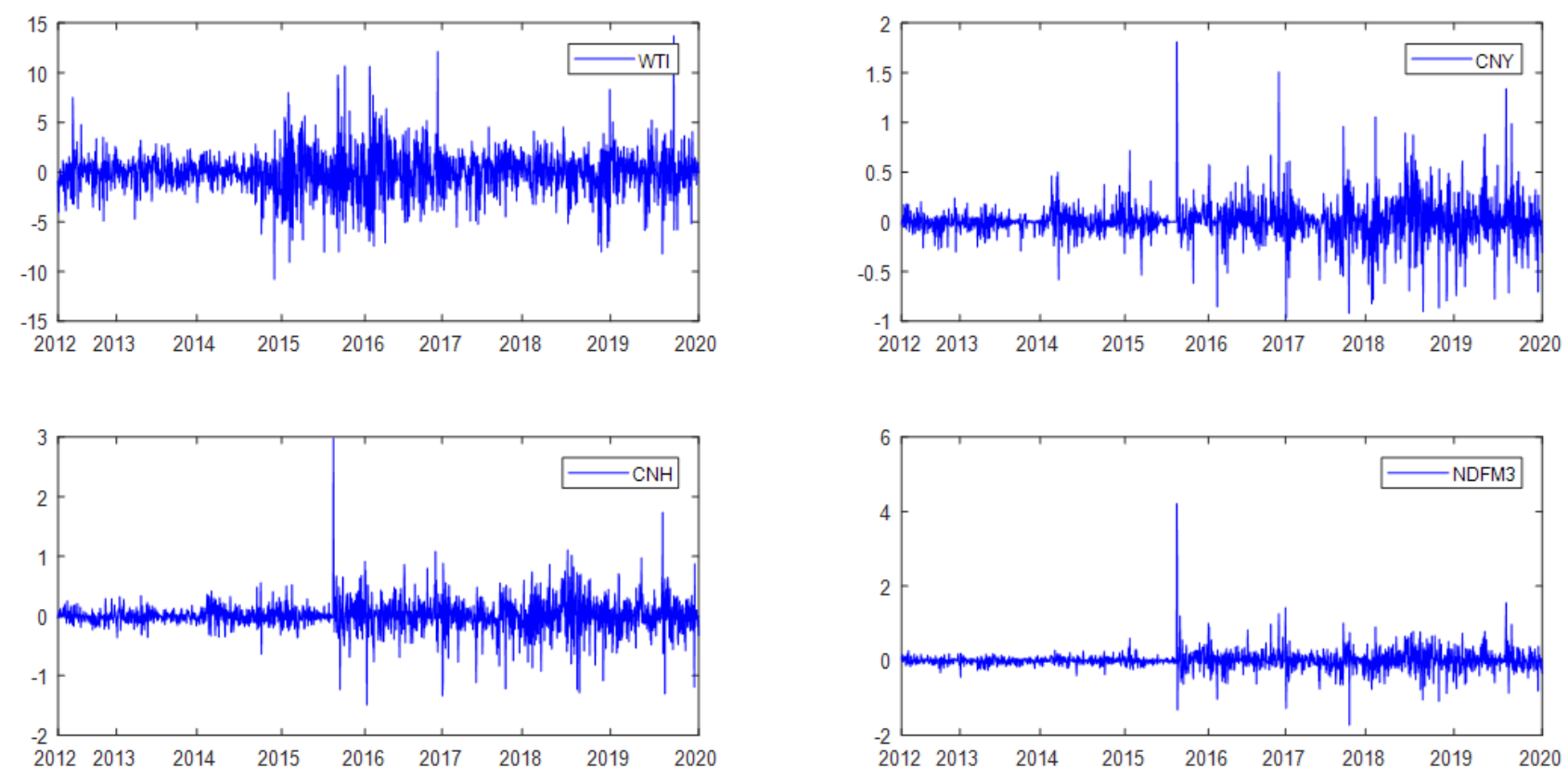

Figure 1. Exchange Rate and Oil Price Yield Timing Chart.

Figure 1 is a sequence diagram of oil prices and exchange rate yields. As can be seen from the chart above, oil prices moved the most, followed by the offshore RMB exchange rate (NDFM3 and $\mathrm{CNH}$ ) and the onshore RMB exchange rate. In terms of range, the oil price fluctuated most dramatically from 2015 to 2017 , while the RMB exchange rate fluctuated more after the "8.11" reform in 2015. 
Table 1. Descriptive Statistics.

\begin{tabular}{c|c|c|c|c}
\hline & WTI & CNY & CNH & NDFM3 \\
\hline Mean & -0.03 & 0.01 & 0.01 & 0.01 \\
\hline Standard deviation & 2.18 & 0.20 & 0.26 & 0.26 \\
\hline Minimum & -10.79 & -0.97 & -1.49 & -1.73 \\
\hline Maximum & 13.69 & 1.81 & 2.98 & 4.21 \\
\hline Skewness & 0.09 & 0.84 & 0.53 & 3.26 \\
\hline Kurtosis & 6.82 & 13.58 & 17.42 & 55.61 \\
\hline JB & $1065.38^{* * *}$ & $8345.38^{* * *}$ & $>10000^{* * *}$ & $>10000^{* * *}$ \\
\hline LBQ(10) & $18.49^{* *}$ & $31.92^{* * *}$ & 7.84 & $19.47 * *$ \\
\hline ARCH (10) & $168.83^{* * *}$ & $69.59^{* * *}$ & $33.18^{* * *}$ & $263.09^{* * *}$ \\
\hline ADF & $-30.86^{* * *}$ & $-29.01^{* * *}$ & $-30.56^{* * *}$ & $-30.30^{* * *}$ \\
\hline PP & $-44.49^{* * *}$ & $-38.81^{* * *}$ & $-42.74 * * *$ & $-39.62^{* * *}$ \\
\hline & & & &
\end{tabular}

$*, * *$ and ${ }^{* *}$ denote rejection of the null hypothesis at $10 \%, 5 \%$ and $1 \%$ significance levels, respectively.

From the mean point of view, the average value of WTI is negative, indicating that the yield of oil futures is negative, the exchange rate mean is positive, indicating that the RMB has been depreciating in recent years. The standard deviation reflects the change in returns. It can be seen that the standard deviation of the yield of oil is the highest and the standard deviation of the yield of RMB onshore spot exchange rate is the lowest, which is consistent with the situation that the oil price changes greatly, the onshore RMB is controlled and the fluctuation is small.

As can be seen from the skewness coefficient, the above data are all right-skewed. The JB test shows that the original assumption of normal distribution is rejected at the $1 \%$ significance level, indicating that the oil price and exchange rate's return are thick-tailed distribution. The LBQ test shows that, in addition to the $\mathrm{CNH}$ market exchange rate earnings, other returns have significant sequence self-correlations. All of the data have an ARCH effect. The ADF test and PP test reject the original assumption of the unit root of all sequences at the $1 \%$ significance level, suggesting that the yield sequences are stable.

\subsection{Static analysis of spillover effects}

Based on the "8.11" exchange rate reform as the demarcation point, we divide the sample into two subsamples before "8.11"reform and after " 8.11 "reform, table 2 is the return spillover table based on the four-variable VAR model

Table 2. Return spillover index based on four-variable VAR.

\begin{tabular}{cccccc}
\hline \multicolumn{6}{c}{ A: before "8.11"reform $(2012 / 5 / 2$ to $2015 / 8 / 10)$} \\
\hline WTI & CNY & CNH & NDFM3 & From others \\
\hline WTI & 99.9780 & 0.0020 & 0.0174 & 0.0026 & 0.0220 \\
CNY & 79.4315 & 11.094 & 7.1929 & 2.2816 & 88.9059 \\
CNH & 78.5507 & 4.7790 & 14.5261 & 2.1442 & 85.4739 \\
NDFM3 & 85.9755 & 2.5610 & 4.8299 & 6.6336 & 93.3664 \\
To others & 243.958 & 7.3420 & 12.0401 & 4.4284 & 267.7683 \\
Total spillovers & 66.9421 & & & & \\
\hline \multicolumn{6}{c}{ B: after "8.11"reform (2015/8/11 to 2019/12/31) } \\
\hline WTI & WTI & CNY & CNH & NDFM3 & From others \\
\hline CNY & 29.8841 & 0.0184 & 0.0639 & 0.0335 & 0.1159 \\
CNH & 27.7084 & 19.751 & 29.8312 & 22.7097 & 80.2494 \\
NDFM3 & 18.8983 & 10.093 & 47.0457 & 20.9632 & 52.9543 \\
To others & 68.4655 & 11.694 & 28.7857 & 40.6613 & 59.3387 \\
Total spillovers & 48.1646 & & 58.6808 & 43.7064 & 192.6583 \\
\hline \multicolumn{7}{c}{}
\end{tabular}


Each column represents the source of the spillover effect, each row represents the direction of the spillover effect. For example, in panel A, the number in Row 3, Column 2 is the return variance contribution from the CNY market to CNH (4.779\%).

From the above table, we can draw the following conclusions. First, overall, the spillover of WTI to exchange rates is significantly higher than the opposite. For example, in panel A, the spillover from WTI to CNY reached $79.43 \%$, but the spillover from CNY to WTI was only $0.002 \%$. Similarly, the spillovers from CNH and NDFM3 to WTI are both less than $1 \%$. Second, the spillover relationships between three RMB exchange rate markets and oil market are different. Whether before or after the reform, the contributions of WTI futures markets to the CNY market are greatest. Among the spillovers from three exchange rate markets to WTI, CNH performs better than NDFM3 and CNY. Third, the spillovers within the exchange rate markets should be mentioned. Whether it is before or after the reform, the spillover from $\mathrm{CNH}$ is the highest of the three exchange rate markets. The return spillover of CNH to CNY and NDFM3 is greater than that of CNY and NDFM3 to CNH. CNH plays an important role in the exchange rate pricing market. Although $\mathrm{CNH}$ market started last, it has a good development trend in recent years with a wider range of participants, and can better reflect the market's expectations on the exchange rate. Fourth, after the reform, the spillover of WTI to the exchange rates decreased significantly. The spillover of WTI to CNY was $79.4315 \%$ before the reform, but was only $27.7084 \%$ after the reform. The spillover of WTI to CNH and NDFM3 also decreased significantly. Fifth, after the reform, the spillover level of exchange rate to WTI slightly increased. For example, the spillover of CNY to WTI was $0.002 \%$ before the reform and $0.0184 \%$ after the reform. Sixth, the spillover within the exchange rate markets changed. After the reform, the overall spillover level of exchange rate markets rose. For example, the spillover of CNY to CNH was $4.779 \%$ before the reform and increased to $10.0928 \%$ after the reform. In addition, the spillover relationship between CNY and NDFM3 also changes. CNY is the net contributor of the spillover $(2.5610 \%-2.2816 \%=0.2794 \%)$ before, but after the reform, CNY is the net spillover recipient $(11.6943 \%-22.7097 \%=-11.0154 \%)$.

\subsection{Dynamic analysis of spillover effects}

The above analysis is static and does not indicate how the spillover changes over time. The following is a dynamic analysis. The method used in this article is rolling window test. The window length is set to be 250 business days. In order to compare the differences between different exchange rates and oil spillover relationships, we put the indexs on a single chart.

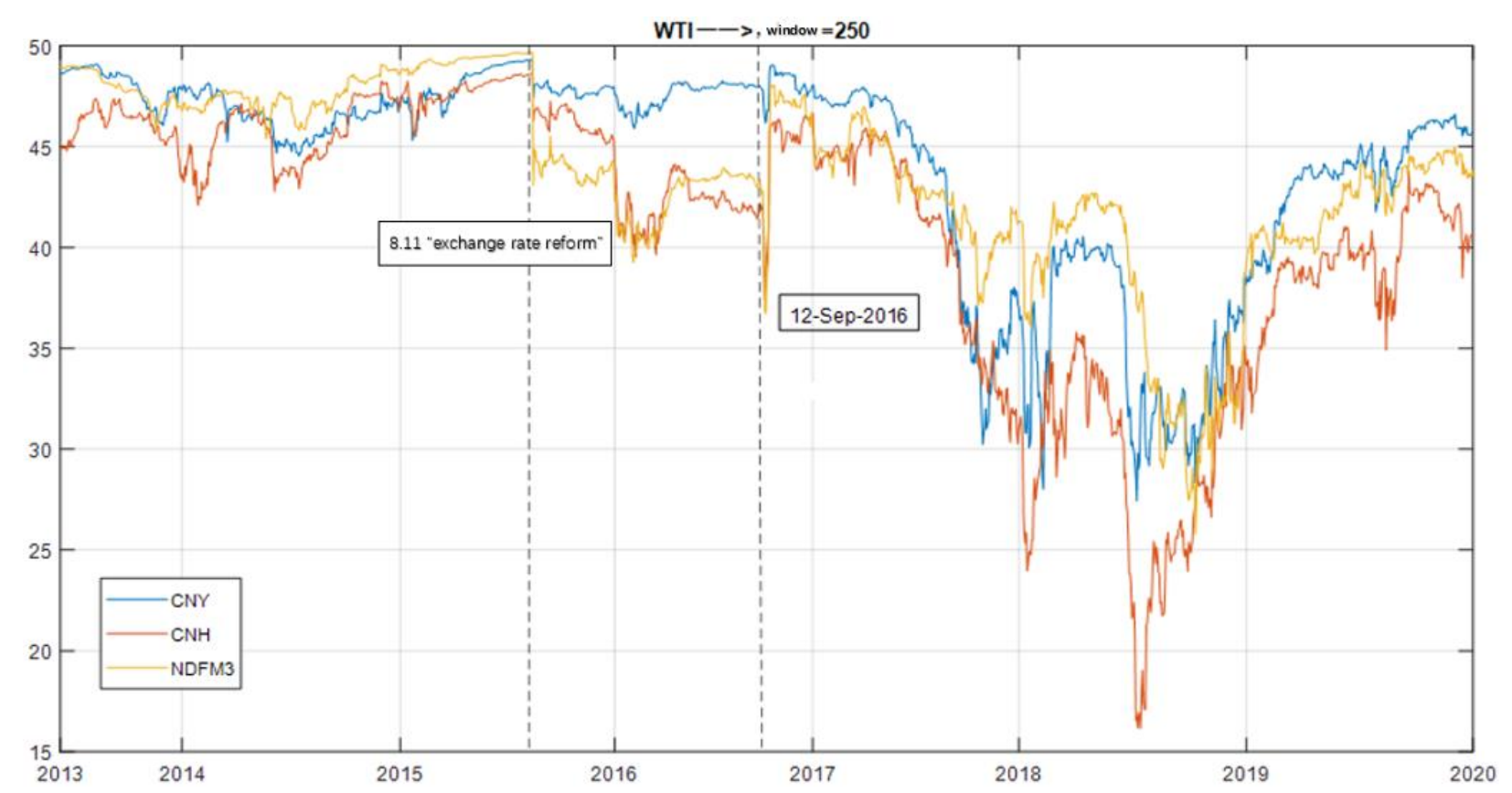

Figure 2. directional return spillovers WTI->CNY/CNH/NDFM3 
Figure 2 shows the dynamic return spillovers of WTI to three exchange rates. During the sample period, the spillover level of WTI to three exchange rates fluctuated between $15 \%$ and $50 \%$, mainly between $30 \%$ and 50\%. The return spillover of WTI to different exchange rates is different. Overall, $\mathrm{CNH}$ gained the least spillover. We can see that the return spillover of oil prices to exchange rates has decreased significantly after the reform.

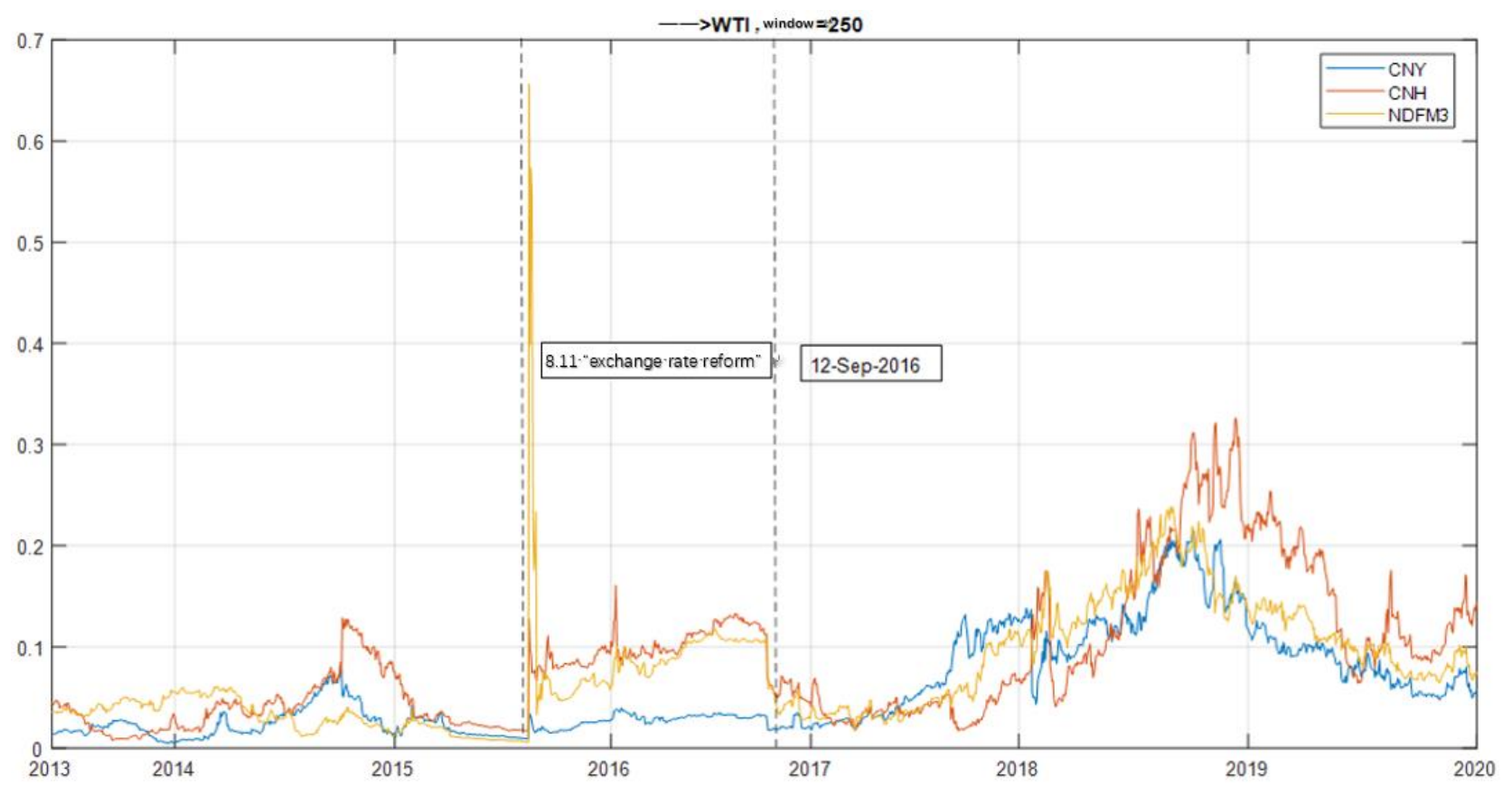

Figure 3. directional return spillovers CNY/CNH/NDFM3-> WTI.

Figure 3 shows the dynamic return spillover of the three exchange rates to WTI. Except during the reform period, most of the spillover level is concentrated in 0-0.3\%. There are slight differences between the spillover of three exchange rates to WTI. During most of the sample period, CNH's spillover level to WTI was slightly higher, and CNY's spillover level was the lowest. The spillover experienced greatest changes during the " 8.11 "reform.

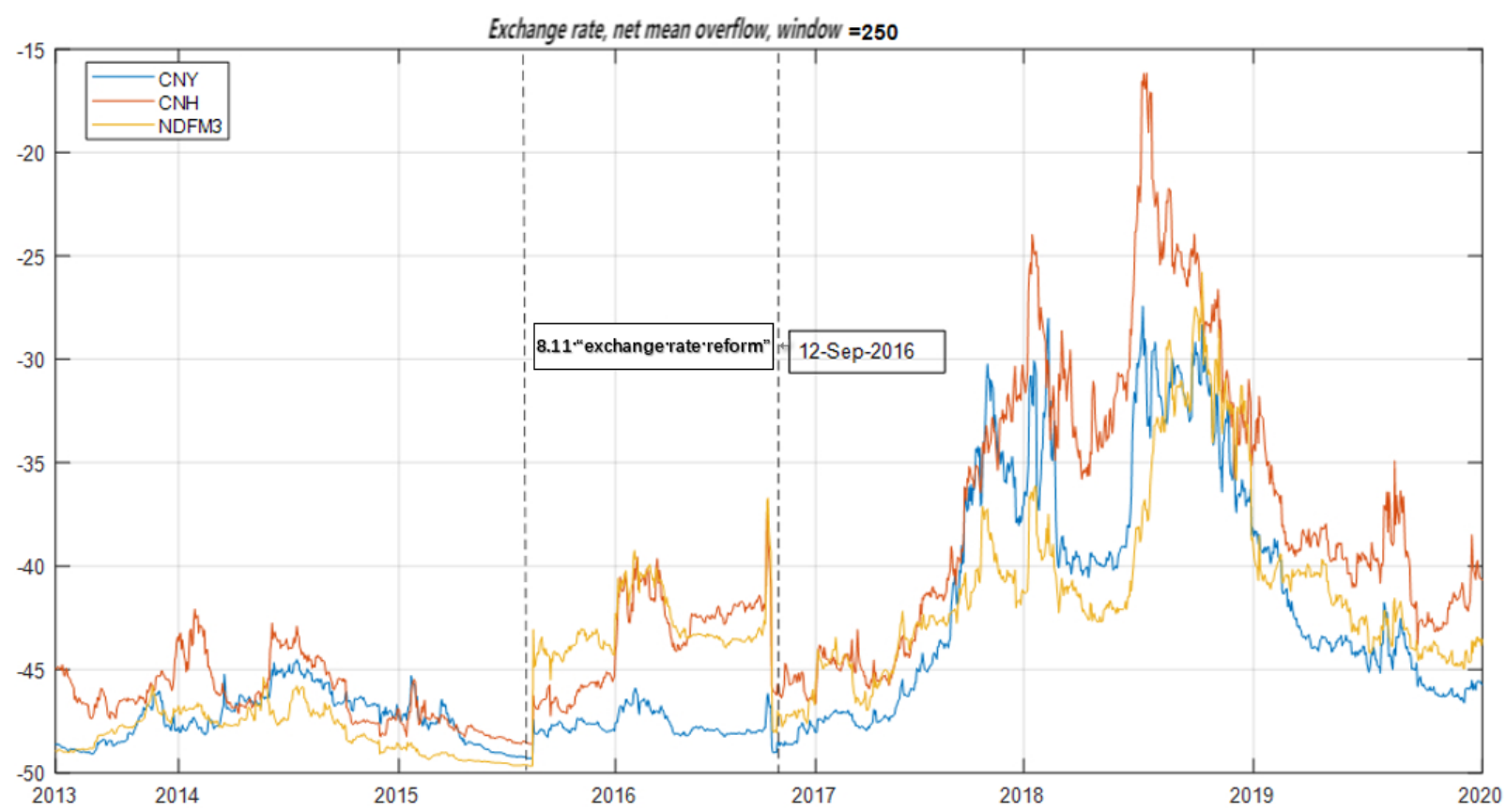

Figure 4. Dynamic Net return spillovers. 
Figure 4 shows the net spillovers of the three exchange rates. The net return spillovers of all three exchange rates are negative, indicating that WTI is the net contributor while exchange rates are the net recipients. Overall, $\mathrm{CNH}$ receives the lowest level of spillover, while CNY receives the highest level. After the reform, the spillover level received by the three exchange rates reduced. In addition, after the reform, the gap between the net spillover levels of the three exchange rates has widened.

\subsection{Robustness test}

The robustness test can be done by replacing variables (swapping the $\mathrm{CNH}$ spot rate for $\mathrm{CNH}$ March or 1-year forward rates, changing the NDF March rate to one-year forwards, and replacing WTI futures prices with Brent crude futures) and changing the rolling window and the steps. We change the rolling window from 250 to 500 days, and find that the overall trend of the spillover graph does not change. The VAR model order used in this article is 10, the robustness section is selected as 2 , and the overall spillover trend does not change. Because charts take up a lot of space, they are no longer shown in this section.

\section{Conclusion}

It can be seen from the above study that there are return spillovers between the oil market and the RMB exchange rate markets. The spillover varies over time, and there is a difference in the spillover of the three exchange rate markets. Specifically:

First, WTI is the contributor of the return spillover. This finding indicates that the oil market plays an important role in RMB exchange rate pricing.

Second, the three exchange rate markets are the recipients of spillover for most of the period, which shows that China's RMB exchange rate is in a passive position in the relationship with international oil prices. Since oil prices are still priced in US dollars, the impact of RMB exchange rate on crude oil prices is very limited. However, at some point in the major policy announcements, the spillover level may change dramatically.

Third, three exchange rate markets differ in the relationship with oil market, but most of the time the differences are very small. The exchange rate markets vary widely in response to some specific news shocks. In terms of return spillover, $\mathrm{CNH}$ gained the least spillover from WTI and contributed the most.

Fourth, return spillover varies over time. After the reform, the return spillover from WTI decreased.

In view of the above analysis and conclusions, we give several recommendations:

First, from the government's point of view, the risk of price fluctuations in the international crude oil market will be transmitted to the RMB exchange rate market through trade channels and capital channels, thus affecting China's macro-economy. In order to reverse this passive situation, on the one hand, China should actively adjust its energy consumption structure, or distribute oil imports reasonably among different oil-producing countries to avoid over-reliance on certain countries. On the other hand, we should speed up the development of the domestic crude oil futures market, actively promote the crude oil to be priced in RMB, enhancing China's pricing power in the international crude oil market.

Second, from the perspective of individual investors, in the process of asset allocation, it is important to note that the international crude oil market is closely linked to the exchange rate market, which will reduce the effect of asset diversification allocation to some extent. Individual investors should also pay close attention to policy trends, important policy releases will bring a huge impact on the market, resulting in sharp market fluctuations.

\section{References}

[1] LIU Ling, FANG Yan, ZHANG Jing-jing. Dynamic Correlations between International Oil Price and RMB Non-deliverable Forwards Returns [J].International trade issues, 2014 (04): 144-154. 
[2] LI Zhibin, ZHANG Wei. Dynamics of Spot Precious Metal Price, Crude Oil Price and RMB Excchange Rate[J].Finance \&Trade Economics,2014(04):48-58.

[3] LIU Jianhe, HAN Chao, CHEN Yutian. The Research on the Risk Spillover Effect between Crude Oil Futures Price and RMB Exchange Rate with Wavelets [J]. Price: Theory \& Practice, 2017(08): 108-111.

[4] LIU Jun. An Empirical Study of the Relationship between the Expectation of RMB Appreciation and International Oil Prices [J]. Journal of Finance and Economics, 2011. 37(01): 91-100.

[5] Diebold, F.X., Yilmaz, K. Better to give than to receive: predictive directional measurement of volatility spillovers [J].International Journal of Forecasting 2012(28):57-66.

[6] Jiang, Y., et al., Visiting the effects of oil price shocks on exchange rates: Quantile-on-quantile and causality-in-quantiles approaches [J]. The North American Journal of Economics and Finance, 2020. 52: p. 101161.

[7] Huang, S., H. and B. Lucey, How do dynamic responses of exchange rates to oil price shocks co-move? From a time-varying perspective [J]. Energy Economics, 2020. 86: p. 104641.

[8] Malik, F. and Z. Umar, Dynamic connectedness of oil price shocks and exchange rates [J]. Energy Economics, 2019. 84: p. 104501. 